\title{
High survival rate of a critically endangered species, the Azores Bullfinch Pyrrhula murina, as a contribution to population recovery
}

\author{
David Monticelli $\cdot$ Ricardo Ceia $\cdot$ Ruben Heleno • \\ Hugo Laborda $\cdot$ Sergio Timóteo $\cdot$ Daniel Jareño $\cdot$ \\ Geoff M. Hilton · Jaime A. Ramos
}

Received: 12 May 2009/Revised: 30 November 2009/Accepted: 1 February 2010/Published online: 26 February 2010

(c) Dt. Ornithologen-Gesellschaft e.V. 2010

\begin{abstract}
This paper reports analyses of a capture-markrecapture (CMR) dataset of 149 Azores Bullfinches ringed on São Miguel island (Azores) between 2005 and 2007, and recaptured-resighted on a monthly basis over a 4-year period (2005-2008) throughout their breeding range. We examined the effect of time, age (adults vs. juveniles), gender (adult males and females), and environmental covariates (temperature, rainfall, NAO index) on survival probabilities. The modelling found a high and constant monthly survival probability (mean $\pm \mathrm{SE}$ ) estimated at $0.96 \pm 0.01$, similar between both adults and juveniles and independent of environmental conditions and gender. These findings agree with expectations from island-based life-history theory where relatively mild conditions and
\end{abstract}

Communicated by P. H. Becker.

D. Monticelli $(\varangle)$

Laboratory of Tropical and Subtropical Forestry, Unit of Forest and Nature Management, Gembloux Agricultural University,

2 Passage des Déportés, 5030 Gembloux, Belgium

e-mail: monticelli.david@gmail.com

R. Ceia $\cdot$ H. Laborda $\cdot$ S. Timóteo $\cdot$ D. Jareño Sociedade Portuguesa para o Estudo das Aves, 105 Av. da Liberdade, 1250-140 Lisbon, Portugal

R. Heleno

School of Biological Sciences, University of Bristol,

Bristol BS8 1UG, UK

G. M. Hilton

Wildfowl \& Wetlands Trust (WWT), Slimbridge,

Glos GL2 7BT, UK

R. Heleno - J. A. Ramos

Institute of Marine Research (IMAR/CMA),

Department of Life Sciences, University of Coimbra,

Apartado 3046, 3001-401 Coimbra, Portugal lack of predators should favour high survival rates to compensate for the low reproductive output. The annual survival rate was estimated at 0.62 , which was also consistent with this pattern when compared with survival estimates of mainland bullfinch and passerine species on other subtropical islands obtained in similar CMR studies. Based on a canonical estimator, the size of the studied population (mean $\pm \mathrm{SE}$ ) was estimated at $1608 \pm 326$ individuals. Given that the population size was only around 120-400 individuals in the early 1990s, we suggest that the high survival probabilities currently applying to this critically endangered species may have substantially contributed to the recent recovery of this population. Future research studies on the species' demography should continue to monitor survival in order to measure the effect of management interventions currently taking place within the range of the Azores Bullfinch, including the restoration of the biodiversity rich laurel forest, but also focusing on nest success, which is important for understanding population dynamics.

Keywords Individual covariates - Mark-recapture · Population management · Pyrrhula murina - Azores . Survival

\section{Introduction}

Understanding the dynamics of animal populations via demographic models and population growth rate $(\lambda)$ estimations is a central theme in applied ecology and conservation biology, but requires the determination of basic vital rates such as fecundity and age-related survival of individuals (Caswell and Fujiwara 2004). Only if these parameters are estimated accurately, based on empirical 
studies, can their population dynamic implications be fully understood and appropriate management decisions taken (Perkins and Vickery 2001; Steifetten and Dale 2006). Survival rates of passerine bird species and the factors that affect them have been documented increasingly over recent decades. Adult survival has been found to vary in relation to individual characteristics (e.g., sex, age, mass; Clobert et al. 1988), density-dependent processes (e.g., Saether et al. 2002), and weather conditions (e.g., Robinson et al. 2007). However, while most of our current knowledge is based on temperate-zone studies, there is little information on the survival of species living in both tropical and subtropical environments and on oceanic islands. Available data suggest that species living in northern temperate regions typically experience lower survival rates than similar taxa from tropical and southern hemisphere species (Peach et al. 2001; Schaefer et al. 2006; McNamara et al. 2008 and references therein). This pattern has been related to several factors, such as stronger seasonal fluctuations in climatic conditions in northern habitats (i.e., harsh winter conditions leading to high winter mortality), and, for nonresident species, the survival costs associated with migration (Møller 2007; McNamara et al. 2008). Compared to their mainland counterparts, passerine species living on oceanic islands have been found to exhibit enhanced survival rates (in both adults and juveniles), but the reasons behind this remain, as yet, uncertain (Faaborg and Arendt 1995; Blondel 2000), although relatively constant climatic conditions throughout the year and a lack of predators on islands may be, at least in part, responsible for the observed differences (Blondel 2000; Brouwer et al. 2006).

The Azores Bullfinch Pyrrhula murina is a critically endangered sedentary species (BirdLife International 2008), whose breeding range is largely restricted to about 1,675 ha of native high-altitude laurel forest in the Azorean oceanic island of São Miguel, North Atlantic Ocean


species seemed abundant in the second half of the nineteenth century (Hartert and Ogilvie-Grant 1905; Bannerman and Bannerman 1966), but became very rare in the first half of the twentieth century (Ramos 1996a). The population was estimated at 60-80 individuals in the 1970s (Le Grand 1983), 200 individuals in 1989 (Bibby and Charlton 1991), and 120-400 individuals in 1991-1993 (Ramos 1996a). From 2002 onwards, annual estimations of abundance through distance sampling fluctuated between 283 (in 2003) and 965 (in 2006) individuals (Ceia 2008). From 1991 to 1993, Ramos (1994) estimated annual adult survival at around 50\% and annual recruitment of first-time breeders at around $45-59 \%$, suggesting a stable population (population growth rate $\lambda \approx 1$ ). However, survival figures did not rely on robust methods (i.e., capture-recapture modelling; CMR), and hence may be underestimated if, for instance, the recapture probability of the species is $<1$. Thus, to support the present efforts made towards the conservation of this critically endangered species (see Ceia 2008), the need for a more recent (and accurate) estimation of demographic rates, and survival in particular, using a CMR approach was stressed. This study should also allow the comparison of Azores Bullfinch survival estimates with published data on the closely related Eurasian Bullfinch Pyrrhula pyrrhula, thus offering a unique opportunity to understand how demographic rates vary between island and mainland species.

A monthly ringing-resighting scheme was conducted between 2005 and 2008 (4 years) throughout most of the breeding range of the Azores Bullfinch, in order to estimate the survival of adult and juvenile (first-year) individuals. Based on life-history theory (Stearns 1992) and on our knowledge of the biology and ecology of the Azores Bullfinch (Ramos 1994, 1996a), we made four predictions:

(1) Survival estimates should be higher than those found in their temperate European counterparts (Eurasian Bullfinch Pyrrhula pyrrhula), which have annual survival of ca. $41 \%$ in adults and ca. $33 \%$ in juveniles (Siriwardena et al. 1999; British Trust for Ornithology 2009)

(2) The less variable weather conditions in the Azores should favour relatively little interannual and seasonal variation in survival, compared to the strong interannual fluctuations reported for Eurasian Bullfinches breeding in Britain, where winter severity is more variable among years (Siriwardena et al. 1999)

(3) Younger, less experienced individuals are less able to cope with adverse conditions than adults (Stearns 1992), hence we expected that juvenile birds would exhibit lower and more variable survival rates than those of adults

(4) Finally, gender-related differences in passerine survival rates are commonly attributed to differential risks of predation on breeding males and females, especially for species in which breeding behaviour and foraging ecology differ markedly between sexes (Post and Götmark 2006); however, assuming that the Azores Bullfinch is relatively predator-free on S. Miguel island, we expected a priori no sex-specific survival difference between breeding males and females.

\section{Methods}

Study area and study species

The Azorean climate is mild and wet, with considerable precipitation during the summer (Silva 2001). The oceanic 
influence stabilizes the temperature with an annual mean of $17.3^{\circ} \mathrm{C}$ and an average relative humidity of $84 \%$ (Silva 2001). Overall, the weather and structure of natural forests in the Azores match those of a subtropical environment (Haggar 1988). The Azores Bullfinch breeding range is restricted to São Miguel island and encompasses the last patches of native laurel cloud forest (covering less than 2,000 ha), mainly found around Pico da Vara summit. For a full description of the study area and the breeding range of the species, see Ramos (1995, 1996a) and Ceia et al. (2009).

\section{Ringing-resighting scheme}

Azores Bullfinches were mist-netted in 2005-2007 from 11 different ringing stations covering ca. $80 \%$ of the entire Azores Bullfinch distribution range (Fig. 1). In order to maximize captures, the position of each ringing station was initially determined according to habitat type, food availability and most recent observations of feeding Azores Bullfinches. Mist-netting efforts varied from 2 to 8 ringing sessions each month from March to October. During each ringing session, seven mist-nets (3 with $6 \mathrm{~m}$ and 4 with $12 \mathrm{~m}$ ) were opened for five consecutive hours, starting shortly before sunrise. Birds were marked at initial capture with a metal ring and a combination of three plastic colour rings (two rings on each tarsus). Whenever possible, age (adult or juvenile) and sex of captured birds were recorded. In this species, juveniles (first-year birds) and adults (age $>1$ year) can be easily distinguished by examining plumage features such as the colour of the cap, since the former typically retain a brown cap at least until November, while the latter have a black cap. The age upon first capture for the sample group of juveniles ( $n=23$ birds) could not be precisely established because no monitoring data on nest success and fledging dates were collected during the study period. Based on our own field notes (i.e., approximate timing of fledging each year and dates of capture of the birds), we could nevertheless estimate that all juvenile individuals were between 1 and 4 months of age upon first capture (i.e., age class 1-4 months). For adults, sexing based on plumage characteristics is virtually impossible, but males are significantly larger than females (Ramos 1998). Gender was assigned only to a subset of 81 individuals, using either a direct or an indirect method. Individuals were sexed in the field as female (existence of a brood patch, $n=34$ ) and male (when birds were caught in pairs during the breeding season and one of the two individuals had a larger wing-length, $n=18$ ), or indirectly in the laboratory through molecular sexing using PCR $(n=29$ individuals) (Griffiths et al. 1998). For these indirect determinations, DNA was extracted with the kit GenElute
Mammalian Genomic DNA (SIGMA) from body feathers collected during ringing sessions.

The recapture dataset consisted of visual resightings made from June 2005 to September 2008 along six survey routes that were established to cover $80 \%$ of the Azores Bullfinch range (Fig. 1). Each route was visited twice a month by a team of trained observers in an attempt to relocate ringed birds and read their colour ring combinations using binoculars. The length of each route varied from 4.1 to $12.3 \mathrm{~km}$ (mean $8.5 \mathrm{~km}$ ), and a survey had an average duration of $6 \mathrm{~h}$, starting at sunrise. Unmarked individuals (i.e., birds wearing no ring) encountered along a route during a survey were also carefully noted by observers (see "Estimation of population size from recapture probabilities"). For the remaining $20 \%$ of the Azores Bullfinch breeding range that was not covered systematically by survey routes (i.e., on the western edge of the range), all existing roads and tracks were opportunistically visited by trained observers in spring and summer months only to search for ringed birds.

\section{Capture-recapture modelling}

Data analysis was performed in MARK (White and Burnham 1999; Cooch and White 2006) using live encounter histories of 149 Azores Bullfinch individuals. The data corresponded to birds ringed as either juveniles (1-4 months old; $n=23$ birds) or adults ( $n=126$ birds), and included records of whether each individual was or was not detected in each month following ringing. Model notation followed the convention used in Lebreton et al. (1992), with apparent survival rate denoted as $\Phi$ and recapture probability as $P$. To investigate the effect of time ( $t$; month), group (e.g., "g2" for juvenile and adult and "sex" for male and female), and age (e.g., "a2" for two age classes) on survival and resighting (recapture) probabilities, a set of models was developed based on biological reasoning (see the models presented in Tables 1 and 2). The effect of environmental covariates on survival was also examined (see below).

First, a set of candidate models was designed to examine potential differences in survival rates among juveniles and adults. Juveniles (first-year birds) were not older than 4 months upon first capture, but their exact ages could not be determined. These birds were treated equally regarding age at first capture (=juvenile group of 1-4 month-old birds). The modelling started with the global model denoted as $\left[\Phi_{\mathrm{g} 2 * t}, P_{\mathrm{g} 2 * t}\right]$, where both survival and resighting rates vary by time (month) and group. By applying constraints to the design matrix, reduced-parameter structures were constructed, including models with an additive effect between group and time, no group effects (timedependent CJS model for pooled groups), and time- 



Fig. 1 Top: map showing the entire range of the Azores Bullfinch, mainly confined to the remaining patches of native laurel forest on São Miguel island (Azores); bottom: study area where individuals were mist-netted (11 stations) during 22 monthly ringing sessions, with three main vegetation types illustrated and tracks surveyed to resight birds (June 2005-September 2008) sketched invariant (constant) survival and/or resighting rates. We also developed models with two age classes in the group of birds ringed as juveniles. In these models, individuals were permitted to survive with constant juvenile survival until a suitable age, at which time their survival became similar to that of adults. For instance, in the model denoted as $\left[\Phi_{\mathrm{g} 2 \mathrm{a} 2}\right.$ $\left.(0-12 / 12+), P_{t}\right]$, the first age class reflects survival over the first year (0-12 months), while in later months juvenile and adult survival rates are modelled in the same way (i.e., the second age class denoted 12+; model 3, Table 1). Because the oldest fledglings were assumed to be up to 4 months old upon first capture, the juvenile survival period corresponded roughly to a first age class spanning 8 recapture occasions ( $=8$ months) following the initial capture.

A subset of 81 breeding adults was of known gender (34 males and 47 females; see the previous section), and this was used to build a second set of candidate models in order to examine possible sex-related differences in survival. The most general model was that in which both survival and recapture rates depended on time, sex and their interactions (model 29, Table 2).

\section{Effect of covariates}

Selected weather covariates that may explain monthly fluctuations in Azores Bullfinch survival probabilities were added as linear constraints during model fitting (Table 1). To describe local-scale weather effects, we used estimated average monthly temperatures (TEMP) and total monthly rainfall (Rainfall) data available for São Miguel (http:// www.windguru.com/int/index.php?sc=289), while the North Atlantic oscillation (NAO) was used as a more global indicator of climate variability in the region (large-scale weather effects). The NAO is a large-scale atmospheric 
Table 1 Models used to assess monthly survival $(\Phi)$ and recapture $(P)$ probabilities in the Azores Bullfinch between May 2005 and September 2008 using all mark-recapture data $(n=149$ birds $)$

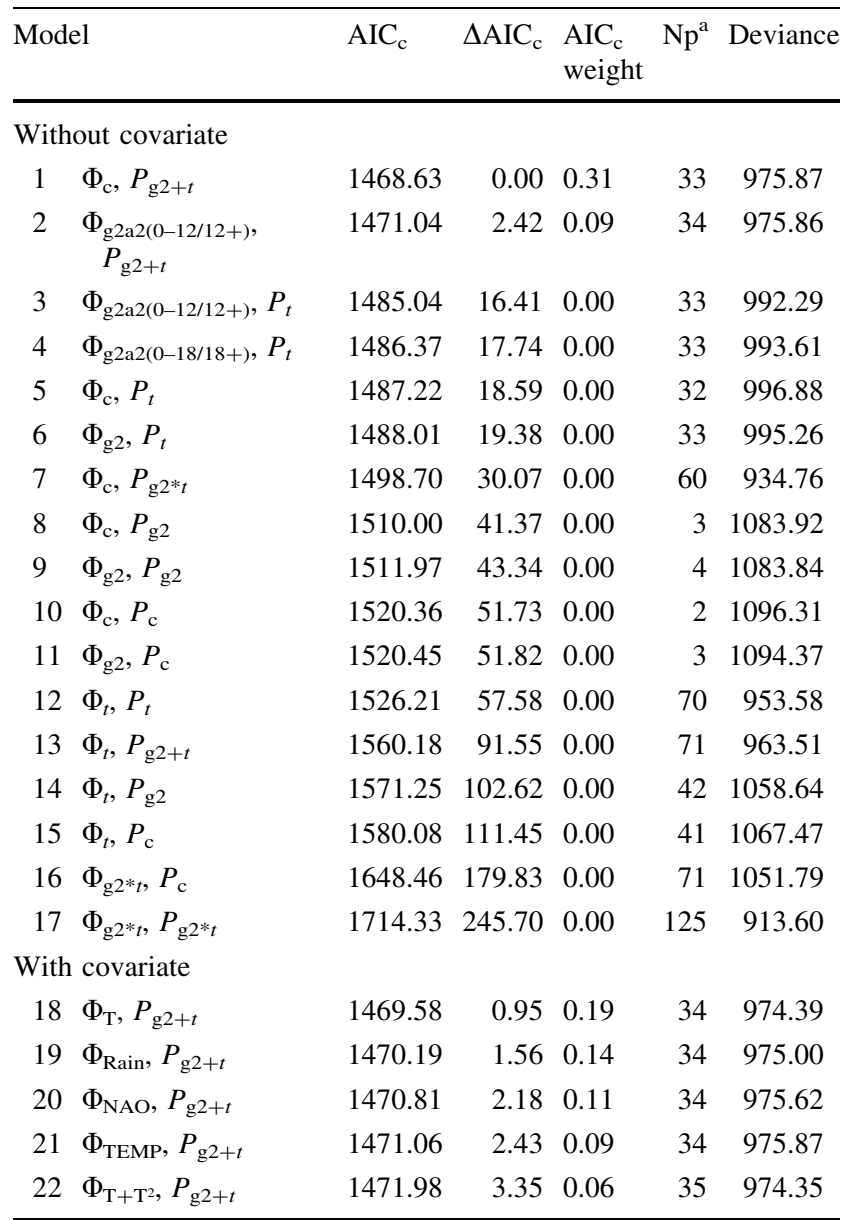

Model development started with the global CJS model, with birds first banded as breeding adults (age $>1$ year old) and as juveniles (fledglings $\leq 4$ month old) treated as separate groups (g2) (model 17). Several reduced-parameter models were fitted to the data by pooling groups, setting time-specific $(t)$ rates to be constant $(c)$ and/or removing interaction terms between time and group (models with an additive effect). In other models, survival was separated into two age classes (g2a2), with juveniles showing constant survival (first age class) until a suitable age where the survival becomes similar to that of adults (second age class) (e.g., model 2). Total rainfall (Rain), average temperature (TEMP), and NAO index (large-scale weather effects) were used as covariates (monthly estimates). Both linear (T) and quadratic temporal $\left(\mathrm{T}+\mathrm{T}^{2}\right)$ trends in survival were also fitted to the data (models 18-22)

${ }^{\text {a }}$ Number of estimable parameters

phenomenon associated with intra- and interannual changes in temperature and precipitation in the North Atlantic (Hurrell 1995); positive values of the NAO index are associated with above-normal temperatures, whereas negative values are associated with below-normal temperatures. Monthly values of the NAO index from May 2005 to August 2008 were obtained from http://www.cpc.ncep.noaa. gov/products/precip/CWlink/pna/nao_index.html. We also
Table 2 Models used to assess monthly survival $(\Phi)$ and recapture $(P)$ probabilities of the Azores Bullfinch between May 2005 and September 2008 using only the subset of breeding adults for which sex was known ( $n=81$ birds)

\begin{tabular}{llrllrl}
\hline Model & \multicolumn{1}{c}{$\mathrm{AIC}_{\mathrm{c}}$} & $\Delta \mathrm{AIC}_{\mathrm{c}}$ & $\mathrm{AIC}_{\mathrm{c}}$ weight & $\mathrm{Np}^{\mathrm{a}}$ & Deviance \\
\hline 23 & $\Phi_{\mathrm{c}}, P_{t}$ & 817.65 & 0.00 & 0.63 & 30 & 584.86 \\
24 & $\Phi_{\text {sex }}, P_{t}$ & 819.96 & 2.31 & 0.20 & 31 & 584.36 \\
25 & $\Phi_{\mathrm{c}}, P_{\text {sex }+t}$ & 820.30 & 2.66 & 0.17 & 31 & 584.71 \\
26 & $\Phi_{\text {sex }}, P_{\text {sex }}$ & 907.30 & 89.65 & 0.00 & 4 & 737.18 \\
27 & $\Phi_{t}, P_{t}$ & 944.88 & 127.23 & 0.00 & 68 & 576.40 \\
28 & $\Phi_{\text {sex }+t, P_{\text {sex* }^{*}}}$ & 1080.88 & 263.24 & 0.00 & 98 & 534.57 \\
29 & $\Phi_{\text {sex* }^{*}, P_{\text {sex }^{*} t}}$ & 1302.63 & 484.98 & 0.00 & 121 & 529.66 \\
\hline
\end{tabular}

Model building procedure started with the global CJS model, with males and females treated as separate groups (sex) (model 29). The monthly survival estimate from the best $\mathrm{AIC}_{\mathrm{c}}$ model (model 23) was $0.9611 \pm 0.0080(0.9419-0.9741)$

${ }^{\text {a }}$ Number of estimable parameters

searched for possible systematic changes in survival over time by fitting both linear and quadratic trends as covariates (denoted " $\mathrm{T}$ " and " $\mathrm{T}+\mathrm{T}$ ", respectively). The significance of each covariate was first examined by checking the $95 \%$ confidence limits (CL) of the slope of the corresponding beta $(\beta)$ parameter.

\section{Goodness-of-fit test and model selection}

Two informative goodness-of-fit (GOF) tests were performed in the program U-CARE 2.2 (Choquet et al. 2005) to check the fits of the global models (models 17 and 29). The GOF test was performed for separate groups (juvenile/ adult; male/female) to detect transience (Test 3.SR) and/or trap dependence (Test 2.CT), followed by a sum of tests (3.Sm, 3.SR, 2.Ct, 2.Cl) over groups to provide a combined chi-square value. Akaike's information criterion (AIC; Akaike 1973; Burnham and Anderson 2002) corrected for sample size $\left(\mathrm{AIC}_{\mathrm{c}}\right)$ was used to select the model that best fitted the data among our sets of candidate models (i.e., the model with lowest $\mathrm{AIC}_{\mathrm{c}}$ ). As a general rule, models differing from the best $\mathrm{AIC}_{\mathrm{c}}$ model by more than 2 units $\left(\Delta \mathrm{AIC}_{\mathrm{c}}>2\right)$ were considered to be poorly supported by the data (Burnham and Anderson 2002). Overdispersion (or extramultinomial variation) in the data may be a cause of lack of fit, and, if warranted, a coefficient referred to as the variance inflation factor $(\hat{c})$ can be applied to adjust $\mathrm{AIC}_{\mathrm{c}}$ values (Williams et al. 2002). $\mathrm{AIC}_{\mathrm{c}}$ weights were also used as they provide a relative measure of how well a model supports the data compared to other models (Burnham and Anderson 2002). The number of estimable parameters for a given model depends on its structure and statistical information provided by the data; in the present dataset, no recapture was available for nine monthly resighting 
sessions due to a near-complete absence of survey, and the corresponding parameters were set equal to zero in MARK (September 2005 to February 2006, May 2006, November 2007, and March 2008). This increased to 11 resighting months when only the subset of 81 adults of known gender was analysed (i.e., adding no recapture in January 2007 and January 2008). Standard errors (SE) of derived parameters were estimated using the delta method. Parameter estimates are presented in the "Results" section as mean \pm SE.

Estimation of population size from recapture probabilities

The monthly capture-recapture probabilities derived from the modelling permit the estimation of abundance (population size) using a canonical estimator (Williams et al. 2002). Considering $n_{i}$ to be the total number of birds caught (ringed and unringed) during sampling period (month) $i$, the number of birds in the population exposed to the sampling effort for that month $i$ was estimated as $\hat{N} i=n i / \hat{p} i$. When the capture-recapture probability is modelled separately for different groups (e.g., adults and juveniles), the abundance can be estimated separately as $\hat{N}_{i}^{s}=n_{i}^{s} / \hat{p}_{i}$, where $s$ denotes group (Williams et al. 2002). In subsequent estimations, only count data and recapture rates of adults were used to estimate population size. Because Azores Bullfinches were captured through mistnetting but recaptured using a resighting method, the number of birds recaptured each month $\left(n_{i}\right)$ also included the number of unringed adults that were encountered by observers. These count data were available from June 2006 onwards. A rough estimate of population size was calculated as the arithmetic mean of the 25 monthly estimates available in this study.

\section{Results}

\section{Sample size and GOF test}

A total of 149 Azores Bullfinches were mist-netted and released during 22 monthly colour-ringing sessions organized from May 2005 to September 2007. Following their initial ringing, 117 individuals (98 adults and 19 juveniles) were resighted or recaptured in a subsequent month, and, overall, the modelling was based on a total of 383 monthly encounters between June 2005 and September 2008 (40 months).

The GOF tests performed in U-CARE provided no evidence for a lack of fit of the full data set (combined $\chi^{2}$ over groups $=89.01, d f=114, P=0.96$ ) and for the subset of adults of known gender (combined $\chi^{2}$ over groups $=48.76, d f=99, P=0.99)$, so no correction of $\mathrm{AIC}_{\mathrm{c}}$ values was applied during model fitting.

Effect of time, age and covariates

Highly parameterized models with time-dependent survival rates, including the global CJS models (models 12-17), were poorly ranked by $\mathrm{AIC}_{\mathrm{c}}$, whereas those with constant survival, where adults and juveniles were either taken as separate groups (models $6,9,11$ ) or as a common pool (models 5, 7, 8, 10), were better supported by the data (Table 1). Furthermore, models incorporating full time dependence in recapture parameters were more parsimonious than those with constant effort (Table 1). Thus, several models with time-invariant survival and time-specific recapture probabilities were fitted to further explore the effect of "group" or "age" (juvenile vs. adult). Among these, models with different survival between juvenile individuals aged less than 12 months (=first-year survival), and adults received substantial support from the data (models 2,3), whilst moving (decreasing or increasing) the age at which juvenile survival becomes similar to that of adults (e.g., model 4) did not result in models with lower $\mathrm{AIC}_{\mathrm{c}}$ values. Model 3 was, however, less plausible than model 2, which included a "group effect" on recaptureresighting parameters. Finally, a model with an additive effect of time and group for recaptures but with the survival rate constant among juveniles and adults showed the best fit to the data, as expressed by $\mathrm{AIC}_{\mathrm{c}}$ values $\left(\Delta \mathrm{AIC}_{\mathrm{c}}=2.42\right.$ for model 1 vs. model 2); the slope $\beta$ for the group effect on recaptures was significant in that model $(\beta=$ $-0.985 \pm 0.208$ with $95 \% \mathrm{CI}:-1.394$ to -0.576 ). This final accepted model (model 1) was $3.44 \times$ better supported by the data than the second-best model (model 2; Table 1).

Model 1 was used as a starting structure to test for covariate effects on survival rates (Table 1). Two competing models, including linear temporal trend and effect of rainfall on survival, were classified within $2 \mathrm{AIC}_{\mathrm{c}}$ units of the starting model (model 1 vs. models 18, 19) and received substantial support from the data, as judged from $\mathrm{AIC}_{\mathrm{c}}$ weights (Table 1). However, the slope $\beta$ (based on a logit link function) of the relationship between survival rate and the covariate was nonsignificant in both cases (i.e., the 95\% confidence limits spanned the value of zero), suggesting that these covariates were not important in explaining the processes that generated the data.

Adult and juvenile survival estimates

The best $\mathrm{AIC}_{\mathrm{c}}$-supported model (model 1) suggested that the survival estimates for adults and juveniles were high and similar, with monthly individual survival estimated at $0.961 \pm 0.006$ (95\%CI: $0.946-0.972$ ). This raised to the 
power of 12 yielded an annual survival rate of 0.62 $( \pm 0.07)$. Resighting rates of this best model (model 1) varied between monthly periods, and were always slightly higher in juveniles than in adults (additive effect between time and group). These resighting probabilities were very low; on average, they were estimated at $0.125( \pm 0.048)$ and $0.252( \pm 0.081)$ for adults and juveniles, respectively.

\section{Effect of gender}

The general models accounting for time dependence and sex-specific difference in survival and resighting probabilities did not perform well, as indicated by $\mathrm{AIC}_{\mathrm{c}}$ values (e.g., models 27, 28, 29, Table 2). Reduced-parameter models with sex-effect or constant survival rates were a better fit to the data (Table 2). In fact, the most parsimonious model was that in which survival was constant and independent of sex, with a time dependence on resighting rates (model 23; Table 2), whereas the second best-ranked model (model 24) had different survivals in males and females but was less favoured by $\mathrm{AIC}_{\mathrm{c}}\left(\Delta \mathrm{AIC}_{\mathrm{c}}=2.31\right)$, being at least $3 \times$ less likely than the top model. The best AIC $_{\mathrm{c}}$-ranked model (model 23) estimated a constant and sex-independent monthly survival of $0.961 \pm 0.008$ (0.942-0.974). This latter estimate was annualised to 0.62 $( \pm 0.07)$, which corresponds to the survival estimate provided by model 1 (Table 1).

\section{Population size}

Based on the resighting probabilities of adults estimated in model 1, the number of Azores Bullfinch adults in the population was calculated for 25 months. The lowest estimate corresponded to June 2006 (296 individuals), whereas the highest figure was obtained in January 2007 (6,983 individuals); however, apart from these two outliers, the estimates ranged from 500 to 2,000 individuals in all other months, and overall the mean population size (mean $\pm \mathrm{SE}$ ) was 1,608 \pm 326 individuals (i.e., 804 pairs considering an unbiased sex ratio).

\section{Discussion}

Our prediction that annual survival rates of adult and juvenile Azores Bullfinches would be higher than those found for their European counterparts was well supported by the data, as the estimate of 0.62 was substantially higher than those reported by Siriwardena et al. (1999) in Britain, namely 0.41 in adults and 0.33 in juveniles (data only available graphically in that paper; see also British Trust for Ornithology 2009). Overall, Azores Bullfinch survival estimates were also high compared to other European finches (Siriwardena et al. 1999) and northern temperate passerines (Schaefer et al. 2006 and references therein), which usually have survival probabilities of $<50-60 \%$. Indeed, our estimates are more comparable to those of tropical passerines (Schaefer et al. 2006), and in particular to those found in similar taxa living on other subtropical islands, such as the Puerto Rican Bullfinch (Loxigilla portoricensis: 0.64; Faaborg and Arendt 1995). We note that the annual survival estimate of 0.46 reported for the Greater Antillean Bullfinch (Loxigilla violacea) on the subtropical island of Andros (Bahamas; Dean 1999) is lower than that reported here for the Azores Bullfinch, despite the similar capture-mark-recapture modelling approaches used in both studies.

\section{Capture-recapture modelling}

The survival estimates found in this study are likely to closely represent true values because the dispersal of individuals out of our study area was probably very low due to the fact that $80 \%$ of the entire breeding range of the species was systematically covered by our resighting scheme. Thus, we believe that our monthly survival probabilities were not confounded by permanent emigration. The annualised adult survival is slightly higher than that found earlier by Ramos (1994), but several explanations may account for this, and these are not mutually exclusive. Ramos (1994) estimated adult survival at 0.50 using ad hoc return rates, a method assuming a recapture probability equal to 1 . As this is rarely the case, the use of return rates may underestimate survival rates (Lebreton et al. 1992; Williams et al. 2002). As further evidence for this, the resighting probabilities found in this study were largely $<1$, suggesting that capture-recapture modelling of the data was a more appropriate approach. Given the sedentary habits and restricted range of the Azores Bullfinch on São Miguel, the resighting (recapture) rates reported here are relatively low, which can be explained in part by a low sampling effort, as survey routes were only visited twice a month. Moreover, Azores Bullfinches are difficult to detect in the dense vegetation of the laurel forest on S. Miguel island (pers. obs.). In fact, we note that many resightings of ringed individuals could not be integrated into the recapture histories, as the durations of observations by field workers were not sufficient to allow the full colour ring combination to be read with confidence. In particular, adult birds are quiet and elusive, while juveniles are tamer (especially during the first months after fledging), which sometimes allowed prolonged observations along surveyed tracks. This probably explains the higher resighting probabilities of juveniles found in our best models.

The high survival rates obtained in this study when compared to the previous estimates of Ramos (1994) may 
also help to explain a slight increase in population size since the 1990s (Ceia 2008). Indeed, demographic rates such as adult survival play an important role in the population dynamics of $K$-selected species, and an increase of the population from 120 to 400 individuals in 1991-1993 (Ramos 1996a) to a current estimate of ca. 1,600 individuals would almost certainly have required a genuine improvement in survival; this increase may have been operating before this study and stabilizing over the last few years, as our modelling failed to detect a linear trend in survival rates between 2005 and 2008. The fact that juveniles show a high survival rate, similar to that of adults (see the "Discussion" below), must be also important for explaining this increase, because this age class can make the strongest contribution (i.e., highest elasticity) to the finite rate of population growth in passerine species (Clark and Martin 2007).

\section{Effect of food availability and weather}

Compared to mainland Eurasian Bullfinches, which show strong interannual differences in survival rates, our prediction of less variable survival rates in the Azores Bullfinch was supported by the data. In fact, the constant monthly survival of Azores Bullfinches over the study period suggests an absence of seasonal variation in survival (i.e., winter survival is not lower than summer survival), and presumably, a low interannual variability. Such a difference may be explained by the extremely oceanic climate of São Miguel, which is subject to less seasonal fluctuations in temperature and precipitations than mainland northern Europe and Britain, thereby contributing to lower seasonal fluctuations in environmental conditions (e.g., food abundance). A detailed study of diet and monthly habitat selection by the Azores Bullfinch was carried out in 1991-1993 (Ramos 1995, 1996a, b), revealing that it relies on a mosaic of habitats that provide different feeding resources seasonally, including exotic species common in disturbed areas located on the edge of the natural laurel forest. Ramos (1996a) reported that food was abundant nearly throughout the year, but that survival could be negatively affected during a short period of food scarcity typically occurring in late winter and early spring, which was more acute in years with late development of flower buds. The main food resources available and exploited at this time of the year by the Azores Bullfinch are seeds of Clethra arborea (lily of the valley tree), flower buds of Ilex perado, and sori of large ferns (Ramos 1996b; Arosa et al. 2009). The former exotic invasive tree species has been expanding its range in recent decades (Ramos 1996a, pers. obs.), providing supplementary feeding resources and perhaps decreasing the risk of food shortage in winter. The absence of temporal variation in survival found in this study supports the hypothesis of a presently fairly constant access to sufficient food resources by this species throughout the year, while the absence of covariate effects (rain, temperature and NAO index) on survival suggests that monthly fluctuations in environmental conditions are too slight to negatively affect the species. In other regions where passerines have easy access to food resources throughout the year, such as in some tropical and southernlatitude regions, survival rates are also stable and high (Covas et al. 2004; Schaefer et al. 2006).

\section{Survival in island species}

Changes in fitness-related traits in insular biota have been attributed to trade-offs among life-history traits in response to high population densities on islands, a characteristic of species-poor insular environments (Blondel 2000). A higher survival rate and a lower clutch size on islands in comparison to mainland areas are two of these characteristics, and some passerine species in tropical islands such as the Seychelles Warbler (Acrocephalus sechellensis) have survival rates as high as $0.83-0.84$ and a clutch size of one egg (Komdeur 1994; Brouwer et al. 2006). The British Trust for Ornithology (2009) reports a clutch size of 4-5 eggs for bullfinches from Britain and Europe, which is larger than the 3-egg clutches for the Azores Bullfinch (based on a sample size of 3 nests; R. Ceia pers. obs.). This suggests that, unless their breeding success is higher, Azores Bullfinches should compensate for this difference by exhibiting either higher adult survival or higher juvenile survival, or both (Martin 1996). Observations of adults accompanied by juveniles in late summer suggest that breeding success is about two young per pair (Ramos 1994; Ceia 1998), which is also lower than that of European Bullfinches (around 3-4 fledglings/pair; British Trust for Ornithology 2009). Thus, the high survival found in this study seems part of a syndrome that includes lower brood size, and is consistent with the patterns described in other island-living passerines.

Contrary to expectations, the survival rate of juveniles was as high as that found in adults, a rather unusual-but not unique - pattern previously reported in several southern-latitude species (Covas et al. 2004 and reference therein). It should be acknowledged, however, that the sample size of juvenile birds used in this study was low (23) compared to that of adults (126), perhaps making the detection of age-related differences more difficult during data modelling. Note also that we estimated survival for a class of juveniles in which some individuals were estimated to be up to 4 months old at first capture; hence, if mortality was high during the early post-fledging period, it could not be detected in our study, and our juvenile estimates would be slightly inflated. Nevertheless, field 
observations suggest a relatively prolonged post-fledging parental care in which recently fledged Azores Bullfinches are still fed by their parents for at least 1-2 months, which is likely to enhance their chances of survival. Juvenile dispersal is also very limited by the restricted range of the species, which should promote high survival (Brouwer et al. 2006).

An important characteristic of islands is the lower number of potential predators when compared to a mainland situation. Historical references suggest that passerine species breeding on São Miguel island were initially predator-free (Fructuoso 1561). There are no avian predators such as sparrowhawks or other small forest raptors on São Miguel. Cats and rats were introduced after the colonisation of the island. However, the few known cases of nest predation (by rats) were on eggs and nestlings (Ceia 2008), but not on flying birds. Sex-biased predation mortality, due particularly to predation of incubating females, has been often reported in passerines (Post and Götmark 2006), but the overall low predation risk on São Miguel may explain the high survival rate of the species, including the similar survival rates of adult males and females.

Since 2002, major management interventions have been taking place on São Miguel Island within the Azores Bullfinch range, including both the restoration of the biodiversity-rich laurel forest and the removal of exotic plants that usually do not provide alternative food resources for the birds (Heleno et al. 2010). Further studies should thus investigate whether the demography of the Azores Bullfinch may, at least in the long term, benefit from an increased availability of natural habitat and food.

\section{Zusammenfassung}

Hohe Überlebensraten einer vom Aussterben bedrohten Art, dem Azorengimpel Pyrrhula murina - ein Beitrag zur Verbesserung der Population

Dieser Beitrag beschreibt Fang-Wiederfang Untersuchungen (Capture-Mark-Recapture, CMR) von 149 Azorengimpeln, die zwischen 2005 und 2007 auf der Insel São Miguel (Azoren) beringt und anschließend monatlich während vier Jahren (2005-2008) im gesamten Brutgebiet wieder gefangen und gesichtet wurden. Wir untersuchten den Einfluss von Zeit, Alter (Altvögel vs Jungvögel), Geschlecht (adulte Männchen und Weibchen), und Umweltvariablen (Temperatur, Niederschlag, NAO Index) auf die Überlebenswahrscheinlichkeit. Unser Model ergab eine konstant hohe monatliche Überlebenswahrscheinlichkeit von $0.96 \pm 0.01$ (Mittelwert \pm SE), ähnlich für Altvögel und Jungvögel und unabhängig von Geschlecht und Umweltfaktoren. Diese Ergebnisse stimmen mit Erwartungen basierend auf der Life-history Theorie für Inselbewohnende Arten überein, die besagen, dass bei milden Bedingungen und fehlender Prädation hohe Überlebenswahrscheinlichkeiten bevorzugt werden, um niedrige Reproduktionsraten zu kompensieren. Die jährliche Überlebensrate wurde auf 0.62 geschätzt, und auch dies ist konsistent zu Schätzwerten der Überlebenswahrscheinlichkeit anhand von CMR Studien an Gimpeln auf dem Festland sowie anderen Singvogelarten auf anderen subtropischen Inseln. Die Größe der untersuchten Population wurde anhand eines kanonischen Schätzwertes auf $1608 \pm 326$ (Mittelwert \pm SE) Individuen geschätzt. Da die Population in den frühen 1990er Jahren nur 120-400 Individuen umfasste, nehmen wir an, dass die momentane hohe Überlebenswahrscheinlichkeit dieser vom Aussterben bedrohten Art substantiell zur Erholung der Population beigetragen hat. Zukünftige Studien zur Demografie dieser Art sollten weiterhin die Überlebenswahrscheinlichkeit berücksichtigen, um die Auswirkungen von Managementeingriffen wie zum Beispiel die Restauration des Loorbeerwaldes, die derzeit auf den Azoren innerhalb des Brutgebietes des Azorengimpels stattfinden, einschätzen zu können. Gleichzeitig sollte jedoch auch der Bruterfolg gemessen werden, da dies zum Verständnis der Populationdynamik ebenfalls wichtig ist.

Acknowledgments We thank everyone involved in the capturemark-recapture data collection on São Miguel between 2005 and 2008 , the Portuguese Society for the Study of Birds and the team from the LIFE-Priolo conservation project, as well as the Administração Florestal at Nordeste for logistic support. We are also indebted to Dr Morten Frederiksen for helpful comments and suggestions during data modelling. Earlier drafts of this paper benefited greatly from the comments of two anonymous reviewers.

\section{References}

Akaike H (1973) Information theory and an extension of the maximum likelihood principle. In: Petran BN, Csaki F (eds) International symposium on information theory. Akademiai Kiadi, Budapest, pp 267-281

Arosa ML, Ramos JA, Valkenburg T, Ceia R, Laborda H, Quintanilla LG, Heleno R (2009) Fern feeding ecology of the Azores Bullfinch (Pyrrhula murina): the selection of fern species and the influence of nutritional composition in fern choice. Ardeola $56: 71-84$

Bannerman D, Bannerman BK (1966) Birds of the Atlantic Islands: a history of the birds of the Azores. Oliver \& Boyd, Edinburgh

Bibby CJ, Charlton TD (1991) Observations on the São Miguel Bullfinch. Açoreana 7:297-304

BirdLife International (2008) Species factsheet: Pyrrhula murina. http://www.birdlife.org, last accessed 16 Apr 2010

Blondel J (2000) Evolution and ecology of birds on islands: trends and prospects. Vie Milieu 50:205-220

British Trust for Ornithology (2009) Birdfacts: Bullfinch Pyrrhula pyrrhula [Linnaeus, 1758]. http://blx1.bto.org/birdfacts/results/ bob17100.htm and http://www.bto.org/birdtrends2008/wcrbullf. shtml, last accessed 16 Feb 2010 
Brouwer L, Richardson DS, Eikenaar C, Komdeur J (2006) The role of group size and environmental factors on survival in a cooperatively breeding tropical passerine. J Anim Ecol 75:1321-1329

Burnham KP, Anderson DR (2002) Model selection and multimodel inference: a practical information-theoretic approach, 2nd edn. Springer, New York

Caswell H, Fujiwara M (2004) Beyond survival estimation: markrecapture, matrix population models, and population dynamics. Anim Biodivers Conserv 27:471-488

Ceia R (2008) Monitorização da população de Priolo. Relatório da acção F6 do Projecto LIFE Priolo. Sociedade Portuguesa para o Estudo das Aves, Lisboa

Ceia R, Heleno R, Ramos JA (2009) Summer abundance and ecological distribution of passerines in native and exotic forests in São Miguel, Azores. Ardeola 56:25-39

Choquet R, Reboulet AM, Lebreton J-D, Gimenez O, Pradel R (2005) U-CARE 2.2 user's manual. CEFE, Montpellier

Clark ME, Martin TE (2007) Modeling tradeoffs in avian life history traits and consequences for population growth. Ecol Model 209:110-120

Clobert J, Perrins CM, McCleery RH, Gosler AG (1988) Survival rate in the Great Tit (Parus major) in relation to sex, age, and immigration status. J Animal Ecol 57:287-306

Cooch EG, White GC (2006) MARK: an introductory guide. http://www.phidot.org/software/docs/book/, last accessed 1 March 2009

Covas R, Brown RC, Anderson MD, Brown MB (2004) Juvenile and adult survival in the sociable weaver (Philetairus socius), a southern-temperate colonial cooperative breeder in Africa. Auk 121:1199-1207

Dean T (1999) Second-growth habitat use and survival rates of migrant and resident land birds, North Andros Island, Bahamas (MSc. thesis). The University of New Brunswick, Fredericton

Faaborg J, Arendt WJ (1995) Survival rates of Puerto Rican birds: are islands really that different? Auk 112:503-507

Fructuoso G (1561) In: Rodrigues JBO (ed) Saudades da Terra, 6 volumes from 1978 to 1983 , 2nd edn. Instituto Cultural de Ponta Delgada, Ponta Delgada (Azores)

Griffiths R, Double M, Orr K, Dawson R (1998) A DNA test to sex most birds. Mol Ecol 7:1071-1075

Haggar JP (1988) The structure, composition and status of the cloud forests of Pico Island in the Azores. Biol Conserv 46:7-22

Hartert E, Ogilvie-Grant W (1905) On the birds of the Azores. Novit Zool 12:80-128

Heleno RH, Lacerda IC, Ramos JA, Memmott J (2010) Evaluation of restoration effectiveness: community response to the removal of alien plants. Ecol Appl (in press)

Hurrell JW (1995) Decadal trends in the North Atlantic oscillation: regional temperatures and precipitation. Science 269:676-679

Komdeur J (1994) Conserving the Seychelles warbler Acrocephalus sechellensis by translocation from Cousin Island to the islands of Aride and Cousine. Biol Conserv 67:143-152

Le Grand G (1983) Der Wiederentdeckte Azorengimpel. Wir und Vogel 15:37-38

Lebreton JD, Burnham KP, Clobert J, Anderson DR (1992) Modeling survival and testing biological hypotheses using marked animals: a unified approach with case studies. Ecol Monogr 62:67-118
Martin TE (1996) Life history evolution in tropical and south temperate birds: what do we really know? J Avian Biol 27:263-272

McNamara JM, Barta Z, Wikelski M, Houston AI (2008) A theoretical investigation of the effect of latitude on avian life histories. Am Nat 172:331-345

Møller AP (2007) Senescence in relation to latitude and migration in birds. J Evol Biol 20:750-757

Peach WJ, Hanmer DB, Oatley TB (2001) Do southern African songbirds live longer than their European counterparts? Oikos 93:235-249

Perkins DW, Vickery PD (2001) Annual survival of an endangered passerine, the Florida Grasshopper sparrow. Wilson Bull 113:211-216

Post P, Götmark F (2006) Predation by sparrowhawks Accipiter nisus on male and female pied flycatchers Ficedula hypoleuca in relation to their breeding behaviour and foraging. J Avian Biol 37:158-168

Ramos JA (1994) The annual cycle of the Azores Bullfinch, Pyrrhula murina Goldman, 1866 (Aves: Passeriformes). Arquipélago. Life Mar Sci 12A:101-109 Ponta Delgada. ISSN 0870-6851

Ramos JA (1995) The diet of the Azores Bullfinch Pyrrhula murina and floristic variation within its range. Biol Conserv 71:237-249

Ramos JA (1996a) Introduction of exotic tree species as a threat to the Azores Bullfinch population. J Appl Ecol 33:710-722

Ramos JA (1996b) The influence of size, shape and phenolic content on the selection of winter foods by the Azores Bullfinch. J Zool 238:415-433

Ramos JA (1998) Biometrics, weights, breeding and moulting seasons of passerines in an Azores cloud forest. Ringing Migr 19:17-22

Robinson RA, Baillie SR, Crick HQP (2007) Weather-dependent survival: implications of climate change for passerine population processes. Ibis 149:357-364

Saether B-E, Engen S, Matthysen E (2002) Demographic characteristics and population dynamical patterns of solitary birds. Science 295:2070-2073

Schaefer H-C, Eshiamwata GW, Munyekenye FB, Griebeler EM, Bohning-Gaese K (2006) Monthly survival of African Sylvia warblers in a seasonally arid tropical environment. Ibis 148:411424

Silva LD (2001) Plantas vasculares invasoras no Arquipélago dos Açores (Ph.D. thesis). University of the Azores, Ponta Delgada

Siriwardena GM, Baillie SR, Wilson JD (1999) Temporal variation in the annual survival rates of six granivorous birds with contrasting population trends. Ibis 141:621-636

Stearns SC (1992) The evolution of life histories. Oxford University Press, Oxford

Steifetten O, Dale S (2006) Viability of an endangered population of ortolan buntings: the effect of a skewed operational sex ratio. Biol Conserv 132:88-97

White GC, Burnham KP (1999) Program MARK: survival estimation from populations of marked animals. Bird Study 46(Suppl):120 139

Williams BK, Nichols JD, Conroy MJ (2002) Analysis and management of animal populations. Academic, San Diego 